\title{
Field Methods to Estimate Fat-free Mass in International Soccer Players
}

\author{
Authors \\ F. Javier Nuñez ${ }^{1}$, Diego Munguia-Izquierdo' ${ }^{1}$, Cristian Petri², Luis Suarez-Arrones
}

\section{Affiliations}

1 University of Pablo de Olavide, Physical Performance \& Sports Research, Seville, Spain

2 Experimental and Clinic Medicine, University of Florence, Florence, Italy

Key words

body composition. DXA, team game, indirect methods

accepted $\quad 19.06 .2019$

\section{Bibliography}

DOI https://doi.org/10.1055/a-0969-8591

Published online: 31.7.2019

Int J Sports Med 2019; 40: 619-624

(c) Georg Thieme Verlag KG Stuttgart · New York

ISSN 0172-4622

\author{
Correspondence \\ Dr. F. Javier Nuñez \\ Department of Sports and Informatics \\ University of Pablo de Olavide of Sevilla \\ Carretera de Utrera km 1 \\ 41013 Sevile \\ Spain \\ Tel.: + 34/606/204 313, Fax: + 34/954/977 534 \\ fjnunsan@upo.es
}

\begin{abstract}
Based on the high financial and logistical costs associated with the assessment of body composition with dual-energy X-ray absorptiometry (DXA), this study determined which field method has the best correlation with DXA data, and developed an equation to estimate fat-free mass (FFM) using the field anthropometric data in international soccer players. A total of 17 international soccer players participated in this study. DXA values provided a criterion measure of FFM. Correlation coefficients, biases, limits of agreement, and differences were used as validity measures, and regression analyses were used to develop the prediction equation. All field methods used to obtain FFM data showed positive correlations ( $r$ from $0.90-0.96$ ) with DXA. Only the equation developed by Deurenberg et al. [6] showed no differences from DXA with a low bias. The main strength of this study was providing a valid and accurate equation to estimate FFM specifically in international soccer players.
\end{abstract}

\section{Introduction}

Soccer is a team sport in which the physical stresses of training and competitive matches across a season modulate players' body composition [1-3]. There is considerable variation in the number of matches played per season in different professional soccer leagues, but of all of the players of the different leagues, the international soccer players played significantly more matches during the season than those who were not international-level [4]. Nevertheless, Carling and Orhant [5] showed that the relationship between matches played and body composition did not demonstrate any significant association in professional soccer players but suggested that variations in body composition across the season are perhaps more likely to be linked to the density or importance of matches. In particular, it is the international soccer players who present a greater density and importance of matches, especially at the end of the season, than those who are not international-level [4].

The body fat mass (FM) and fat-free mass (FFM) assessed by dual-energy X-ray absorptiometry (DXA) are probably the most evaluated body composition components in soccer [1-3, 6-12]. A recent study showed that during a season, FM was not different between squads, whereas FFM was greater in elite professional players compared with elite young players [3]. There is evidence of FFM positional differences between goalkeepers and outfield players [3], but no differences between the specific positions were apparent when considering FFM in outfield players [2,3]. Therefore, an adequate relative FFM in outfield elite soccer players is needed to satisfactorily execute the high-intensity movement patterns demanded during matches and training. Multiple studies have as- 
sessed FFM using DXA in young [3, 7] and professional soccer players [1-3], but we have no evidence of the existence of studies of international soccer players.

DXA provides a reliable method for assessing FFM in elite professional soccer players [1-3], but its high costs do not allow frequent use [10]. In soccer it is therefore more common to use lower-cost methods such as bioelectrical impedance analysis (BIA) and anthropometric measurements (circumference, skinfold, and breadth) to estimate FFM [7]. Few studies have used anthropometric equations in professional players to predict FFM $[5,13]$, but only one, which compared its data with DXA, has determined which method is more effective in elite youth male soccer players [7]. As far as we know, we have no record of the application of these methods to international soccer players. Consequently, the aims of this study were determine which field method has the best correlation with DXA FFM data, and to develop an equation to estimate FFM using the field anthropometric data in international soccer players.

\section{Materials and Methods}

\section{Subjects}

Seventeen international soccer players participated in this study. The mean \pm SD age, height, body mass and body mass index were $29.3 \pm 3.1$ years, $1.84 \pm 0.06 \mathrm{~m}, 78.8 \pm 4.7 \mathrm{~kg}$, and $23.1 \pm 1.1$, respectively. All players evaluated had played in the entire last season with their respective senior national teams. Data were collected during the end of the domestic competition (i. e., Serie A, Italy). The study procedures were approved by the Ethics Committee of the institutions involved, and meet the ethical standards of the journal [14].

\section{Procedure}

This was a cross-sectional validation study in which the height, body mass, FFM (BIA), skinfolds, circumferences, breadths, and FFM (DXA) of the participants were measured using standardized procedures in the aforementioned order. The FFM estimations from BIA measurements and anthropometric equations were compared against DXA to determine the validity of these practical methods for use in international soccer players. A multiple regression analysis was used to generate an FFM prediction equation in international soccer players. Participants were instructed to follow their standard food and fluid protocol, present in a rested, fasted and hydrated state, finish their last meal at least $2.5 \mathrm{~h}$ before the measurement, and arrive with an empty bladder [15]. Likewise they should avoid strenuous exercise, alcohol, stimulants, or depressants for $24 \mathrm{~h}$ prior to testing [7]. Each participant undertook an identical assessment session for 30-45 minutes on different days.

\section{Bioelectrical impedance analysis (BIA)}

Before BIA measurement, the participants' palms and soles were wiped with an electrolyte tissue. The BIA measurements were taken using Tanita MC-180 MAIII (Tanita Corp., Tokyo, Japan) devices. The body mass was measured with the players standing with their soles in contact with the foot electrodes of the Tanita MC-180 MAIII scales. Participants grasped the hand grips while placing their fingers in the standard location. The analysis of the FFM started when the participant was immobile in the position described previously. The mean of two measures was used for analysis.

\section{Anthropometry}

Stature was measured with a stadiometer (seca 213; seca, Hamburg, Germany) with an accuracy of $0.5 \mathrm{~cm}$. Body mass was measured with an electronic scale (OHAUS Corp., Florham Park, NJ, USA) with an accuracy of $0.1 \mathrm{~kg}$. The formula for the body mass index (BMI) was body mass $(\mathrm{kg}) /$ height $\left(\mathrm{m}^{2}\right)$. Six circumferences (calf, thigh, waist, hip, relaxed arm and flexed arm), eight skinfold thicknesses (medial calf, anterior thigh, iliac crest, abdominal, subscapular, supraspinale, biceps, and triceps), and two bone biepicondylar breadths (femur and humerus) were measured with a tape, skinfold calliper, and calliper (Holtain, Crymych, United Kingdom), respectively. All anthropometric measurements were taken according to standard methods [16]. The mean of two measures of each anthropometric variable was used for analysis. Ten equations were used to estimate the percentage of FM [8,17-25]. The Siri equation [10] was used to estimate the percentage of body fat when the body density was calculated from an equation. FM was subtracted from body mass to obtain FFM $(0.1 \mathrm{~kg})$.

\section{Dual-energy X-ray absorptiometry (DXA)}

A DXA scanner (Hologic QDR Series, Delphi A model; Bedford, MA, USA) with software (Hologic APEX software version 13.3:3) was used to calculate FFM in accordance with the DXA best-practice guidelines described previously [26]. The participants were in a supine position with hands level with the hips and feet slightly apart. FFM was obtained by the sum of the lean soft tissue mass and bone mineral content, and was calculated from whole-body scans without the head. The FFM coefficient of variation for repeated measures was $<3.3 \%[27]$.

\section{Statistical analyses}

Descriptive statistics were calculated for each variable. Relative and absolute technical error of the measurements were calculated [28]. The normality of the distribution of the data was verified by the Shapiro-Wilk test. To compare FFM between DXA, BIA data and skinfold equations, the paired t-test, Pearson correlation $( \pm 90 \%$ $\mathrm{Cl})$, bias, limits of agreement, standardized differences $( \pm 90 \% \mathrm{Cl}$ ), and qualitative differences were used. Correlation coefficients were qualitatively ranked by magnitude as follows: trivial, $r<0.1$; small, $0.1<r<0.3$; moderate, $0.3<r<0.5$; large, $0.5<r<0.7$; very large, $0.7<r<0.9$; almost perfect, $0.9<r<1.0$; and perfect $r=1.0$ [29]. The effect size of the standardized differences in FFM was determined by Cohen's d statistic, and Hopkin's scale was used to determine the magnitude of the effect size, where $0-0.2=$ trivial, $0.2-$ $0.6=$ small, $0.6-1.2=$ moderate, $1.2-2.0=$ large, and $>2.0=$ very large [29]. The probability of a true difference between methods was qualitatively classified as almost certainly not, $<0.5 \%$; very unlikely, 0.5-5\%; unlikely, 5-25\%; possibly, 25-75\%; likely, 75-95\%; very likely, 95-99.5\%; and almost certainly, >99.5\%. A substantial effect was set at $>75 \%$ [30]. If the chance that the true value is $>25 \%$ beneficial and $>0.5 \%$ chance that it is harmful, the clinical effect was considered as unclear.

The Statistical Package for the Social Sciences (SPSS 2010, IBM SPSS Statistics 19 Core System User's Guide; SPSS, Inc., Chicago, 
IL, USA) was used to perform the stepwise regression analyses. FFM (DXA) as the dependent variable and the anthropometric variables that significantly correlated with FFM (DXA) were introduced as the predictor variables to obtain the best model for predicting FFM in an international soccer-specific equation. Significance was set at $\mathrm{p}<0.05$.

\section{Results}

The physical characteristics of the participants are shown in $>$ Table 1. The technical errors of measurements were $\leq 2.78 \%$ for skinfold measurement and $\leq 0.52 \%$ for circumferences and bone breadths (

Correlations; biases; limits of agreement; systematic, standardized, and qualitative differences between DXA FFM; and other practical estimates of FFM for international soccer players are shown in - Table 3. All skinfold equations and BIA FFM data showed a positive correlation ( $r$ from $0.90-0.96$ ) with DXA. Only one set of equations showed no standardized or substantial differences compared with DXA and had the lowest bias [18].

Only the relaxed arm, flexed arm, hip circumferences, and humerus breadth showed a significantly large to very large positive correlation with DXA-derived FFM ( $r$ from 0.53 to 0.71 ; all $p<0.05$ ) ( $\triangleright$ Table 4). All skinfolds and all sums of skinfolds showed no correlation with DXA-derived FFM. The different models for the stepwise

- Table 1 Physical characteristics of the participants $(n=17)$.

\begin{tabular}{|c|c|c|}
\hline & Mean & SD \\
\hline Age $(y)$ & 29.3 & 3.1 \\
\hline Weight $(\mathrm{kg})$ & 78.8 & 4.7 \\
\hline Height (cm) & 184 & 6 \\
\hline $\mathrm{BMI}\left(\mathrm{kg} / \mathrm{m}^{2}\right)$ & 23.3 & 1.1 \\
\hline \%FM by DXA with head & 13.6 & 1.8 \\
\hline FFM by DXA without head & 68.1 & 4 \\
\hline \multicolumn{3}{|l|}{ Skinfolds (mm) } \\
\hline Triceps & 7.1 & 2.1 \\
\hline Subscapular & 8.2 & 0.9 \\
\hline Biceps & 3.1 & 0.4 \\
\hline Iliac crest & 8.4 & 1.6 \\
\hline Supraspinale & 5.7 & 0.8 \\
\hline Abdominal & 4.8 & 0.9 \\
\hline Anterior thigh & 7.4 & 1.7 \\
\hline Medial calf & 6 & 0.9 \\
\hline \multicolumn{3}{|l|}{ Circumferences $(\mathrm{cm})$} \\
\hline Arm relaxed & 28.9 & 1.7 \\
\hline Arm flexed & 30.7 & 1.5 \\
\hline Waist & 76.6 & 2.4 \\
\hline Hip & 94.9 & 1.7 \\
\hline Thigh & 53.9 & 1.5 \\
\hline \multicolumn{3}{|l|}{ Breadths $(\mathrm{cm})$} \\
\hline Humerus & 6.31 & 0.74 \\
\hline Femur & 7.66 & 0.36 \\
\hline
\end{tabular}

$\mathrm{BMI}=$ body mass index; \%BF = percentage of body fat; $F F M=$ fat-free mass; DXA= dual X-ray absorptiometry. linear regression analysis are shown in $>$ Table $\mathbf{5}$. The main predictor of FFM was relaxed arm circumference. An equation including relaxed arm and hip circumference showed an adjusted $R^{2}$ value of $0.65(p<0.05)$. The developed equation is as follows: FFM $(\mathrm{kg})=-66.388+(1.121 \times$ relaxed arm circumference $)+(1.029 \times$ hip circumference), where circumferences are expressed in centimetres.

\section{Discussion}

The aims of this study were to determine which field method has the best correlation with DXA FFM data, and to develop an equation to estimate FFM using the field anthropometric data in international soccer players. The main findings of this study were as follows: 1) the adult equation developed by Deurenberg et al. [18] applied to international soccer players was accurate and highly correlated with DXA FFM data; 2 ) the data obtained by Deurenberg equations was the least biased compared to other field methods; 3 ) the relaxed arm circumference was the best predictor of FFM in our cohort; and 4) relaxed arm and hip circumference variables were included in the equation to estimate FFM in international soccer players.

Skinfold thickness equations and BIA data were similar predictors of DXA-derived FFM but underestimated FFM compared with DXA-derived FFM in international soccer players. However, it seems relevant to emphasize that these equations were developed from data collected on more heterogeneous samples with a low range of FFM. All field estimations of FFM used in this study showed almost perfect correlation values with DXA FFM data, but the biases indicate that we should be cautious when using them for FFM esti-

- Table 2 Coefficient of variation, absolute and relative technical error of measurement for anthropometric variables in international-level elite soccer players $(n=17)$.

\begin{tabular}{|c|c|c|}
\hline & $\begin{array}{l}\text { Absolute } \\
(\mathrm{mm})\end{array}$ & $\begin{array}{l}\text { Relative } \\
(\%)\end{array}$ \\
\hline \multicolumn{3}{|l|}{ Skinfolds } \\
\hline Triceps & 0.14 & 1.64 \\
\hline Subscapular & 0.12 & 3.95 \\
\hline Biceps & 0.12 & 2.06 \\
\hline Iliac crest & 0.19 & 2.25 \\
\hline Supraspinale & 0.13 & 2.66 \\
\hline Abdominal & 0.22 & 2.99 \\
\hline Anterior thigh & 0.22 & 3.73 \\
\hline Medial calf & 0.22 & 3.73 \\
\hline \multicolumn{3}{|c|}{ Circumferences (cm) } \\
\hline Arm relaxed & 0.26 & 0.91 \\
\hline Arm flexed & 0.16 & 0.53 \\
\hline \multicolumn{3}{|l|}{ Waist } \\
\hline Hip & 0.21 & 0.27 \\
\hline Thigh & 0.23 & 0.42 \\
\hline \multicolumn{3}{|l|}{ Breadths (cm) } \\
\hline Humerus & 0.03 & 0.54 \\
\hline Femur & 0.04 & 0.55 \\
\hline $\begin{array}{l}\mathrm{BMI}=\text { body ma } \\
\text { mass; } \mathrm{DXA}=\mathrm{du}\end{array}$ & of body fa & $=$ fat-free \\
\hline
\end{tabular}


- Table 3 Cross-sectional validity between criterion (DXA) fat-free mass and other practical estimates of fat-free mass in international-level elite soccer players $(n=17)$.

\begin{tabular}{|l|l|c|c|c|c|}
\hline $\begin{array}{l}\text { Estimates of } \\
\text { fat-free mass }\end{array}$ & Correlation $\mathbf{( 9 0} \% \mathbf{C l})$ & Bias ( \pm LoA) & $\begin{array}{l}\text { Standardised } \\
\text { differences } \mathbf{( 9 0} \% \mathbf{C L})\end{array}$ & \multicolumn{2}{|c|}{ Qualitative assessment } \\
\hline BIA Tanita & $0.93(0.85 ; 0.97)$ & $7.59^{*}( \pm 3.34)$ & $1.74(0.15)$ & Almost certainly & $100 / 0 / 0$ \\
\hline Slater et al. & $0.96(0.90 ; 0.98)$ & $-16.48^{*}( \pm 2.73)$ & $-4.65(0.12)$ & Almost certainly & $0 / 0 / 100$ \\
\hline Oliver et al. & $0.95(0.89 ; 0.98)$ & $9.38^{*}( \pm 2.62)$ & $2.13(0.10)$ & Almost certainly & $100 / 0 / 0$ \\
\hline Durnin et al. & $0.95(0.89 ; 0.98)$ & $6.21^{*}( \pm 2.62)$ & $1.44(0.11)$ & Almost certainly & $100 / 0 / 0$ \\
\hline Faulkner et al. & $0.95(0.90 ; 0.98)$ & $7.45^{*}( \pm 2.79)$ & $1.72(0.13)$ & Almost certainly & $100 / 0 / 0$ \\
\hline Carter et al. & $0.94(0.87 ; 0.98)$ & $10.24^{*}( \pm 2.98)$ & $2.31(0.14)$ & Almost certainly & $100 / 0 / 0$ \\
\hline Deurenberg et al. & $0.90(0.78 ; 0.96)$ & $0.53( \pm 3.46)$ & $0.13(0.18)$ & Unclear & $0 / 100 / 0$ \\
\hline Withers et al. & $0.95(0.89 ; 0.98)$ & $9.17^{*}( \pm 2.65)$ & $2.09(0.12)$ & Almost certainly & $100 / 0 / 0$ \\
\hline Lohman et al. & $0.94(0.87 ; 0.98)$ & $10.32^{*}( \pm 3.04)$ & $2.33(0.13)$ & Almost certainly & $100 / 0 / 0$ \\
\hline Reilly et al. & $0.95(0.88 ; 0.98)$ & $8.06^{*}( \pm 2.80)$ & $1.85(0.13)$ & Almost certainly & $100 / 0 / 0$ \\
\hline Yuhasz et al. & $0.95(0.87 ; 0.98)$ & $9.26^{*}( \pm 2.89)$ & $2.11(0.13)$ & Almost certainly & $100 / 0 / 0$ \\
\hline
\end{tabular}

Significant differences between criterion (DXA) fat-free mass and others practical estimates of fat-free mass using paired $\mathrm{t}$-test ${ }^{*}$. $\mathrm{Cl}=$ confidence interval; $\mathrm{LoA}=$ level of agreement; $\mathrm{CL}=$ confidence level; $\mathrm{BIA}=$ bioelectrical impedance analysis.

- Table 4 The relationship between criterion (DXA) whole-body fat-free mass and the different anthropometric variables in elite youth male soccer players $(n=17)$.

\begin{tabular}{|c|c|c|}
\hline & Correlation & $P$ value \\
\hline \multicolumn{3}{|l|}{ Skinfolds } \\
\hline Triceps & -0.18 & 0.485 \\
\hline Subscapular & 0.14 & 0.570 \\
\hline Biceps & 0.07 & 0.769 \\
\hline Iliac crest & -0.05 & 0.842 \\
\hline Supraspinale & 0.07 & 0.771 \\
\hline Abdominal & -0.25 & 0.327 \\
\hline Anterior thigh & 0.09 & 0.726 \\
\hline Medial calf & -0.25 & 0.316 \\
\hline $\begin{array}{l}\text { ¿4 skinfolds (triceps, subscapular, } \\
\text { supraspinale, abdominal) }\end{array}$ & -0.10 & 0.691 \\
\hline $\begin{array}{l}\Sigma 4 \text { skinfolds (triceps, subscapular, } \\
\text { biceps, iliac crest) }\end{array}$ & -0.08 & 0.748 \\
\hline $\begin{array}{l}\text { ¿4 skinfolds (triceps, abdominal, } \\
\text { anterior thigh, medial calf) }\end{array}$ & -0.14 & 0.576 \\
\hline$\Sigma 5$ skinfolds & 0.03 & 0.892 \\
\hline$\Sigma 6$ skinfolds & -0.08 & 0.756 \\
\hline$\Sigma 7$ skinfolds & -0.08 & 0.751 \\
\hline$\Sigma 8$ skinfolds & -0.07 & 0.762 \\
\hline \multicolumn{3}{|l|}{ Circumferences $(\mathrm{cm})$} \\
\hline Arm relaxed & 0.70 & 0.002 \\
\hline Arm flexed & 0.57 & 0.017 \\
\hline Waist & 0.07 & 0.789 \\
\hline Hip & 0.68 & 0.003 \\
\hline Thigh & 0.39 & 0.112 \\
\hline \multicolumn{3}{|l|}{ Breadths $(\mathrm{cm})$} \\
\hline Humerus & 0.51 & 0.037 \\
\hline Femur & 0.06 & 0.813 \\
\hline
\end{tabular}

$\Sigma 5$ skinfolds = triceps, subscapular, biceps, iliac crest, anterior thigh; $\Sigma 6$ skinfolds = subscapular, triceps, supraspinale, abdominal, anterior thigh, medial calf; $\Sigma 7$ skinfolds = biceps, subscapular, triceps, supraspinale, abdominal, anterior thigh, medial calf; $\Sigma 8$ skinfolds = biceps, subscapular, triceps, iliac crest, supraspinale, abdominal, anterior thigh, medial calf. mates in international soccer players. Similar results were obtained in an analysis of youth male soccer players [7] in which three skinfold equations were suggested to assess FFM. Our findings suggest that the equation proposed by Deurenberg et al. [18] is a more valid practical method for use in international soccer players. Skinfolds do not seem to be appropriate to predict FFM in international soccer players because they were not included in the equation proposed by Deurenberg et al. [18] or our international soccer-specific prediction equation. The FFM in international soccer players was better determined by other anthropometric parameters, most likely because this population is characterized by low FM $[3,10,31]$ and tends to remain relatively FM-stable throughout the inter-season [5, 32].

Hip, relaxed and flexed arm circumferences, and humerus breadths showed large significant correlations with DXA FFM data. The statistical relationships from circumferences can be explained because they are influenced by the conditioning and training received by soccer players during the season's phases [2]. Milanese et al. [2] argued that the maximal strength training and endurance strength conditioning focused on the lower limbs during the preseason, but limited changes in lower limbs and significantly increased FFM in the trunk and upper limbs were found at mid- and end-season time points. Despite being a relatively stable sample in terms of its anthropometric variables [31,32], it could be possible that the time chosen for the anthropometric measurement (i. e. mid-and end-season) could have influenced the data obtained $[2,5]$.

The relative FFM values in the lower limbs, trunk, and upper limbs in soccer players, are very important to execute the locomotor activities, jumps, kicks and flight that the game demands $[16,31]$. Nevertheless, only relaxed arm and hip circumference variables were included in the equation to estimate FFM in international soccer players. This equation explains more than $65 \%$ of the variance in DXA FFM, although additional research is needed to reduce errors and increase accuracy in estimating FFM in this population. 
- Table 5 Stepwise regression analysis predicting fat-free mass (DXA without head) from anthropometric variables in international-level elite soccer players $(n=17)$.

\begin{tabular}{|c|c|c|c|c|c|c|c|c|}
\hline Model & $\mathbf{R}$ & $\mathbf{R}^{2}$ & Adjusted $\mathrm{R}^{2}$ & SEE & $R^{2}$ change & $\mathbf{F}$ & F change & $\begin{array}{l}\text { Significant } F \\
\text { change }\end{array}$ \\
\hline 1 & 0.697 & 0.485 & 0.451 & 2.893 & 0.485 & 14.149 & 14.149 & 0.002 \\
\hline 2 & 0.807 & 0.652 & 0.602 & 2.463 & 0.166 & 13.102 & 6.689 & 0.022 \\
\hline
\end{tabular}

The present study does have several limitations. DXA FFM assessment has some limiting factors because it does not provide information about muscle water or glycogen content, which may influence the estimation of FFM. We instructed the participants to arrive in a standardized condition to minimize the influence of these variables on the determination of FFM. This study was limited to a single valuation of FFM, so it is necessary to perform longitudinal studies to determine if the deposits found are sensitive to changes in FFM throughout the season.

\section{Conclusion}

The BIA and all equations used in this study to estimate FFM showed high correlation values with DXA data, but only the equation developed by Deurenberg et al. [18] did not underestimate FFM compared with the FFM obtained by DXA. In addition, the study provided a valid and accurate equation to estimate FFM specifically in international soccer players.

\section{Conflict of Interest}

Authors declare that they have no conflict of interest.

\section{References}

[1] Devlin BL, Kingsley M, Leveritt MD, Belski R. Seasonal changes in soccer players' body composition and dietary intake practices. J Strength Cond Res 2017; 31: 3319-3326

[2] Milanese C, Cavedon V, Corradini G, De Vita F, Zancanaro C. Seasonal DXA-measured body composition changes in professional male soccer players. J Sports Sci 2015; 33: 1219-1228

[3] Milsom J, Naughton R, O'Boyle A, Iqbal Z, Morgans R, Drust B, Morton JP. Body composition assessment of English Premier League soccer players: A comparative DXA analysis of first team, U21 and U18 squads. J Sports Sci 2015; 33: 1799-1806

[4] Ekstrand J, Walden M, Hagglund M. A congested football calendar and the wellbeing of players: Correlation between match exposure of European footballers before the World Cup 2002 and their injuries and performances during that World Cup. Br J Sports Med 2004; 38: 493-497

[5] Carling C, Orhant E. Variation in body composition in professional soccer players: Interseasonal and intraseasonal changes and the effects of exposure time and player position. J Strength Cond Res 2010; 24: 1332-1339
[6] Lopez-Taylor JR, Gonzalez-Mendoza RG, Gaytan-Gonzalez A, Jimenez-Alvarado JA, Villegas-Balcazar M, Jauregui-Ulloa EE, Torres-Naranjo F. Accuracy of anthropometric equations for estimating body fat in professional male soccer players compared with DXA. J Sports Med (Hindawi Publ Corp) 2018; 2018: 6843792

[7] Munguia-Izquierdo D, Suarez-Arrones L, Di Salvo V, Paredes-Hernandez V, Ara I, Mendez-Villanueva A. Estimating fat-free mass in elite youth male soccer players: Cross-validation of different field methods and development of prediction equation. J Sports Sci 2018; 37: 11971204

[8] Reilly T, George K, Marfell-Jones M, Scott M, Sutton L, Wallace JA. How well do skinfold equations predict percent body fat in elite soccer players? Int J Sports Med 2009; 30: 607-613

[9] Silvestre R, West C, Maresh CM, Kraemer W]. Body composition and physical performance in men's soccer: A study of a National Collegiate Athletic Association Division I team. J Strength Cond Res 2006; 20: 177-183

[10] Suarez-Arrones L, Petri C, Maldonado RA, Torreno N, Munguía-Izquierdo D, Di Salvo V, Méndez-Villanueva A. Body fat assessment in elite soccer players: Cross-validation of different field methods. Sci Med Football 2018; 2: 203-6208

[11] Sutton L, Scott M, Wallace J, Reilly T. Body composition of English Premier League soccer players: Influence of playing position, international status, and ethnicity. J Sports Sci 2009; 27: 1019-1026

[12] Wittich A, Oliveri MB, Rotemberg E, Mautalen C. Body composition of professional football (soccer) players determined by dual X-ray absorptiometry. J Clin Densitom 2001; 4: 51-55

[13] Owen AL, Lago-Penas C, Dunlop G, Mehdi R, Chtara M, Dellal A. Seasonal body composition variation amongst elite European professional soccer players: An approach of talent identification. J Hum Kinet 2018; 62: 177-184

[14] Harriss DJ, Macsween A, Atkinson G. Standards for ethics in sport and exercise science research: 2018 update. Int J Sports Med 2017; 38: 1126-1131

[15] Yamada Y, Nishizawa M, Uchiyama T, Kasahara Y, Shindo M, Miyachi M, Tanaka S. Developing and validating an age-independent equation using multi-frequency bioelectrical impedance analysis for estimation of appendicular skeletal muscle mass and establishing a cutoff for sarcopenia. Int J Environ Res Public Health 2017; 14: E809

[16] Marfell-Jones MJ, Stewart AD, de Ridder JH.International Standards for Anthropometric Assessment. Wellington, New Zealand: International Society for the Advancement of Kinanthropometry, 2012. Available at http://hdl.handle.net/11072/1510

[17] Carter JL, Body composition of Montreal olympic athletes. In Carter JEL, ed. Physical Structure of Olympic Athletes. Basel: Karger Publishers; 1982: 107-116

[18] Deurenberg P, Weststrate JA, Seidell JC. Body mass index as a measure of body fatness: Age- and sex-specific prediction formulas. Br J Nutr 1991; 65: 105-114 
[19] Durnin JV, Womersley J. Body fat assessed from total body density and its estimation from skinfold thickness: Measurements on 481 men and women aged from 16 to 72 years. Br J Nutr 1974; 32: 77-97

[20] Faulkner JA. Physiology of swimming. Res Q 1966; 37: 41-54

[21] Lohman TG. Skinfolds and body density and their relation to body fatness: A review. Hum Biol 1981; 53: 181-225

[22] Oliver JM, Lambert BS, Martin SE, Green JS, Crouse SF. Predicting football players' dual-energy X-ray absorptiometry body composition using standard anthropometric measures. J Athl Train 2012; 47: 257-263

[23] Slater G], Duthie GM, Pyne DB, Hopkins WG. Validation of a skinfold based index for tracking proportional changes in lean mass. $\mathrm{Br}$ J Sports Med 2006; 40: 208-213

[24] Withers RT, Craig NP, Bourdon PC, Norton KI. Relative body fat and anthropometric prediction of body density of male athletes. Eur J Appl Physiol Occup Physiol 1987; 56: 191-200

[25] Yuhasz MS. The Effects of Sports Training on Body Fat in Man with Predictions of Optimal Body Weight [Dissertion]. Urbana-Champaign, IL: University of Illinois; 1962

[26] Nana A, Slater G], Hopkins WG, Halson SL, Martin DT, West NP, Burke LM. Importance of standardized DXA protocol for assessing physique changes in athletes. Int J Sport Nutr Exerc Metab 2016; 26: 259-267
[27] Calbet JA, Moysi JS, Dorado C, Rodriguez LP. Bone mineral content and density in professional tennis players. Calcif Tissue Int 1998; 62: 491-496

[28] Ulijaszek S], Kerr DA. Anthropometric measurement error and the assessment of nutritional status. Br J Nutr 1999; 82: 165-177

[29] Hopkins WG, Marshall SW, Batterham AM, Hanin J. Progressive statistics for studies in sports medicine and exercise science. Med Sci Sports Exerc 2009; 41: 3-13

[30] Batterham AM, Hopkins WG. Making meaningful inferences about magnitudes. Int J Sports Physiol Perform 2006; 1: 50-57

[31] Reilly T, Bangsbo J, Franks A. Anthropometric and physiological predispositions for elite soccer. J Sports Sci 2000; 18: 669-683

[32] Aziz AR, Newton MJ, Tan H, Teh K. Variation in fitness attributes of players during a competitive season in an Asian professional soccer league: a field-based investigation. Asian J Exerc Sports Sci 2006; 3: 40-45Marfell-Jones MJ, Stewart AD, de Ridder JH.International Standards for Anthropometric Assessment. Wellington, New Zealand: International Society for the Advancement of Kinanthropometry, 2012. Available at http://hdl.handle.net/11072/1510 